\title{
Shakespeare in the Apps: Mobile Technology in Education Context
}

\author{
Amy Suen and Andy Fung
}

\begin{abstract}
Since 2009, more than 40 million iPhone and iPad users have downloaded more than 1 billion apps through the App store. The drastic increase in the use of mobile applications has formed new ways of English Language Arts education. In recent years, the representation of William Shakespeare, the English poet and playwright legacies such as books, poems, plays and birthplace has also been extended to mobile applications. Learning Shakespeare's works through mobile devices will move learning out of the classroom and into the learner's real and virtual environments which has raised the interest among language educators. This paper describes a project which examines the current developments in mobile learning applications of English literature with a focus on Shakespeare-related apps. Apps related to Shakespeare listed in iTunes were explored. We discuss the different types of apps that are applicable to language art learning. Based on Naismith, et al.'s mobile learning research, the learning theories that are related to this new medium are identified and discussed.
\end{abstract}

Index Terms-Education, teaching English, Shakespeare, mobile learning, mobile apps.

\section{INTRODUCTION}

Smartphones have the strongest sales growth in the global mobile market in recent years. 153.9 smartphones are sold in the world in 2012 [1]. Alongside the pervasiveness of smartphones, mobile applications are becoming popular. More than 40 million iPhone and iPad users have downloaded more than 1 billion apps through the App store since 2009 [2]. People use apps not only because they could provide immediate service, feature, or experience for commercial purposes [2] but also improve access to learning and hence, promote new learning.

The drastic increase in the use of mobile applications has formed a new way for learning. Learning through mobile applications could be regarded as mobile learning or m-learning [3]. It refers to all the learning possibilities with any portable, lightweight devices that are small to be held in one's hand or place in a pocket [3]. It has raised the interest among language educators as mobile devices are easily accessible, portable and ubiquitous. Mobile learning moves learning outside classroom and extend learner's experience to real and virtual contexts [4]. Learners could enjoy dynamic multimedia experiences and search for context specific resources.

An initial review of the existing literature of mobile learning shows that there is no one single definition of mobile

Manuscript received February 23, 2015; revised April 23, 2015.

The authors are with the Department of English, the Hong Kong Polytechnic University, Hung Hom, Kowloon, Hong Kong (e-mail: amy.oy.suen@polyu.edu.hk, andyfung00@hotmail.com). learning. Mobile learning is known in many different terms namely, m-learning, personalized learning, ubiquitous learning, u-learning, learning while mobile, anytime/anywhere learning, and handheld learning. Definitions of mobile learning have proceeded from different starting points. Research studies of mobile learning mainly focused on mobility. These studies defined mobile learning as any training with the use of mobile devices including mobile phones, digital audio players, voice recorders, cameras, etc. For instance, mobile learning is defined as the use of pervasive handheld technologies, and wireless networks, to improve and broaden the scope of learning and teaching. It means that mobile learning can be in anywhere such as, classrooms, dining rooms or buses [5]. Similarly, mobile learning is regarded as any learning activities that occurred when the learner took the benefits of the learning opportunities provided by mobile technologies in which learners could involve in educational activities without the constraints of physical location [6]. Mobile learning is defined as e-learning which could be in anywhere at any time with the employment of mobile communication devices, for example, an iPod, a personal digital assistant (PDA), and a mobile phone [7]. These definitions focused on mobility and are technocentric in which they concentrated on the size of mobile devices.

Some studies investigated the use of content for mobile learning employing learning object metadata (e.g. [8]-[11]). There are research examining how library systems were used international standard content in mobile environments to facilitate e-learning ([12], [13]) and the manipulation of mobile devices for teaching and online learning ([8], [14]-[16]). In the context of Hong Kong, different projects of mobile learning were done by tertiary institutions, for example, So examined teaching and learning with SMS in the Hong Kong Institute of Education and suggests that SMS was the most popular access model for mobile learning [17]. The University of Hong Kong had designed mobile games for the Beijing Olympic Equestrian so that students could learn the history of Olympic Games and equestrian events [18].

In addition to the growing popularity of employing mobile applications in tertiary education, a shift of teaching practices in primary and secondary schools was also recognized. In our own initial foray of newspapers, an increasing number of schools had prepared for mobile apps learning ([19], [20]). Schools nowadays are willing to allocate more resources in purchasing mobile learning equipment for teachers and students in which tailor-made mobile applications are produced so as to enhance students' learning motivations. All these suggest that mobile learning is gaining popularity in the recent decade. It is interesting to explore the exploitation of 
mobile learning technologies through Shakespeare mobile applications for English language arts education.

\section{SHAKESPEARE IN HONG KONG}

Though the literary merits of the Shakespeare's works have long been recognised, teaching students with the Bard's work has not been a trend in Hong Kong. In a news article by South China Morning Post exploring the current situation of teaching Shakespeare's works in Hong Kong, Gary Harfitt, a University of Hong Kong teaching consultant in the Education Faculty's Division of Language and Literature argued that teachers were reluctant in teaching English with the Bard's works. In his view, one of the reasons is that teachers generally hold a misconception that Bard's works are only suitable to students with a high English proficiency. Students with a lower proficiency would therefore, not be able to understand the English vocabulary in the prose. Such a misconception held by teachers thus hindered students' development on their self-esteem and confidence in speaking English as well as improving their pronunciation. It is suggested that studying Shakespeare could enhance students' understanding of the English language such as learning well-known phrases that are commonly used in modern English [21]. Such a view is in line with the findings of a survey conducted in 2005 - 2006 by University of Hong Kong (HKU)'s Policy 21 Limited Research Unit concerning the effectiveness of conducting Shakespeare drama classes. The survey findings indicate that $93 \%$ of the teachers believed that learning Shakespeare dramas would increase students' confidence in speaking English; 77\% of students expressed that there was a boost of confidence in speaking English; and $85 \%$ of them believed that their pronunciation had enhanced.

\section{DEVELOPMENT OF SHAKESPEARE LEARNING MATERIALS}

With the advancement of technology, learning Shakespeare is no longer static but has been evolving from printed texts to other media which are more dynamic such as television, film, websites and mobile apps. The use of media like television, film, animation in teaching Shakespeare has been addressed in literature. For example, Tashman argued that 'watching TV show was a meaninglessly passive activity' [22]. Kissler on the other hand, advocated the use of film in teaching Shakespeare, claiming that videotapes could be 'amazingly simple one to teach at almost any level' [23]. In her discussion, Kissler detailed her own approach in integrating videotapes with other classroom activities like students' mock interviews and assignments etc. These studies show the different teaching vehicles of Shakespeare in 1960s other than merely using print texts. At the same period of time, teaching materials of Shakespeare have been started to be digitalized.

"Digital Shakespeare" refers to Shakespeare's texts in electronic form [24]. It began in 1960s in West Germany where there was a team led by Marvin Spevack designed a massive concordance to Shakespeare's complete works [24]. The concordance was run by computers but it was slow in which the texts had to be input by a double entry key-punching system [24]. It was not interactive and was merely a large, printed object with nine volumes. The concordance has later evolved into a sophisticated database with a great pool of lexical information which allows users to search Shakespeare's complete work by morphemes, words, syntax and characters [24]. The corpus is now available in CD-ROM which helps linguistic analysis of characters, for example, the linguistic features of nobility and commoners [24]. In addition to the development of Shakespeare concordance in CD-ROM, the database of Shakespeare's plays had been extended to hypertext in 1990s in which texts could be interlinked and users could search every word occurrence, read footnotes and commentary by clicking the mouse [24]. Later, hypertext had also evolved into multimedia format which allowed digital Shakespeare to move beyond texts to incorporate moving images as well [24].

In the 21 st century, Shakespeare's works have been migrated from websites to mobile applications. Similar to the medium like film, comics, television and websites, mobile applications developers have recognized the educational value in teaching Shakespeare. Numerous Shakespeare-related apps are produced such as audio books, quizzes and famous quotes. Teachers and students could enjoy and expose themselves to the entirety of work through mobile devices. Though there is a spur of research studies focusing on mobile application [25], many of the scholarly interests have centred on the technical issues ([26], [27]), rather than educational apps which have considerable potential to shed light on the way how technology can enhance students' learning abilities. This paper seeks to make a unique contribution to this rapidly developing field by investigating the mobile applications from an educational point of view. In particular, it seeks to discuss relevant learning theories of some educational apps. As suggested by Small, teachers of English language art are required to exploit a variety of materials instead of merely relying on a single textbook [28], this paper will highlight how these educational apps could aid and supplement the English language arts curriculum.

\section{MOBILE LEARNING THEORIES}

Our study discusses Shakespeare's mobile apps by mobile learning theories namely, behaviourism, cognitivist learning, situated learning, collaborative learning, informal and lifelong learning, and learning and teaching support [29]. Table I summarizes the different theories and examples of studies.

TABLE I: MOBILE LEARNING THEORIES AND EXAMPLES

\begin{tabular}{ll}
\hline \hline Theories & Examples of research \\
\hline Behaviourist & {$[30],[31]$} \\
Constructivist & {$[32]-[34]$} \\
Situated learning & {$[35],[36]$} \\
Collaborative learning & {$[37]$} \\
Informal and lifelong learning & {$[38],[39]$} \\
Learning and teaching support & {$[40]$} \\
\hline \hline
\end{tabular}

In the behaviourist learning paradigm, learning stresses the 
reinforcement of the relation between a specific stimulus and response [41]. Mobile learning could enhance behaviourist learning process through stimulus, response and feedback procedures. Teachers use mobile devices to illustrate knowledge or questions (stimulus), learners respond to the materials (response), and the mobile device provides appropriate feedback to learners (reinforcement). The drill and feedback tasks can be regarded as an example of the behaviourist learning paradigm, for instance, the use of PDAs and mobiles for language learning [30] and the provision of feedback on multiple choice through classroom response systems [31].

Constructivist learning is concerned with the construction of new notions building on existing and prior knowledge [32]. Constructivist approach regards learning as an active process in which learners create new ideas based on their knowledge. With mobile devices serving as supporting tools, learners could be active constructors of knowledge in a real-life context. Instances could be found when students examine problems in an environment with GPS in portable personal computer [34] and the adoption of PDAs to model the transmission of a virus [33].

Situated learning refers to the tasks that support learning within an authentic context [42]. Learning is knowledge acquisition as well as an experience of social participation. Learners are presented with knowledge in authentic situations and they learn by participating in the community of practice. Mobile devices could be used for situated learning with the context-aware applications such as the use of PDA for field studies such as taking photographs, taking observation notes and processing data; iPods for listening to instructions in field-based activities; and pocket personal computer in museums for having interactive audio-visual tour. Examples of situated learning are the exploitation of PDAs for investigating ecosystem [35] and pocket personal computers to listen to commentary and watch videos [36].

Collaborative learning promotes learning by social interaction which could be realised by the use of mobile devices for interactions and collaboration between learners [29]. Mobile devices allow learners to share files, data and messages. Cortez, et al. proposed a system of collaborative learning with mobile computers to support teachers in high schools to arrange classroom activities and analyse students' performance [37].

Informal and lifelong learning suggest that learning can happen anytime which mean learning outside a formal curriculum [29]. Informal learning can be planned through learning projects [43] or unplanned, by televisions, newspapers, observations, conversations, etc. Mobile devices offer informal learning support because of their portable nature which makes them easy for recording and sharing information. Lifelong learning happens when learners enhance their knowledge through continuing vocational and professional education in their lifetime [1]. Examples of informal and lifelong learning are young learners using mobile phones to play quizzes and read stories with interactive features [38], and the sending of audio-visual breast cancer information to patients' PDAs during their course of treatments [39].

Learning and teaching support refers to activities that coordinate learners and organize learning resources [29]. Mobile devices could help teachers for organising teaching schedules, materials, and students' data more effectively. Examples of mobile devices which support learning and teaching are teachers using PDAs to keep students' record of participation, scores and make lesson plans [40].

It would be beyond the scope of this paper to offer an in-depth account of all the learning theories and research studies of mobile learning. Yet, the above summary of the major theories and examples of mobile learning offers some theoretical background for exploring the cases of Shakespeare apps. Our project examines 100 Shakespeare apps. The data were collected in July 2012 from the App Store from iTunes.

\section{LEARNING WITH SHAKESPEARE APPS - CS HAMLET}
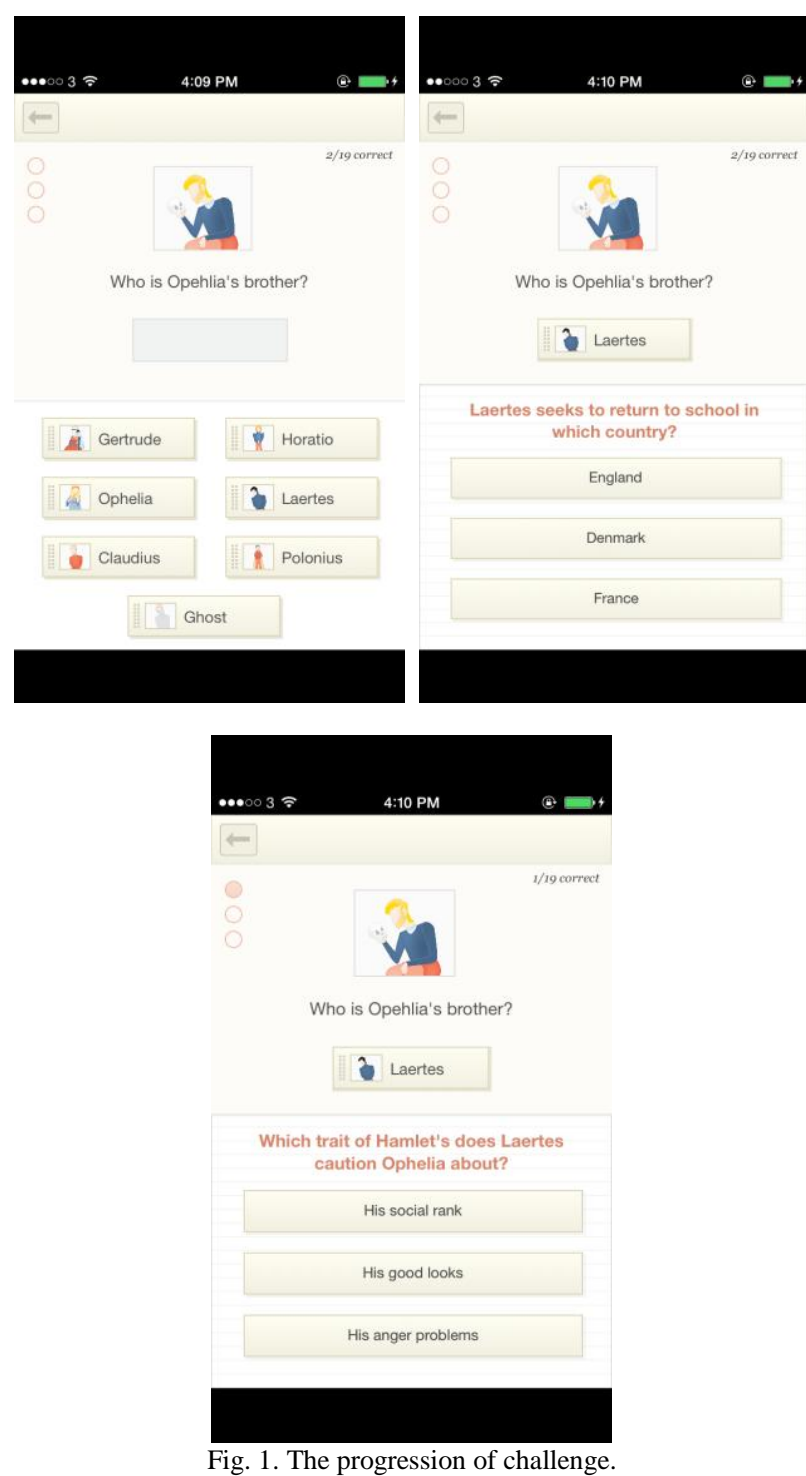

This section shows an example of learning Shakespeare with mobile technologies based on learning theories discussed in the previous section. This example was selected because they support novel and interesting learning activities of Shakespeare which are different from the tradition learning in classrooms. Playing computer games is popular among young adults and gaming can encourage thinking, reflecting and creativity [38] Behaviorist learning is embodied in the 
app CS Hamlet. As aforementioned, behaviorist learning concerns with the stimulus and response so that learning is achieved through association and reinforcement [44]. In CS Hamlet, the questions related to the story Hamlet are constructed as the primary stimulus, and the multiple choices are regarded as the secondary stimulus. Students are required to associate the questions and the answers as a pair. Such association, in turn reinforces their understanding of Hamlet. CS Hamlet, at that same time, reinforces students' understanding by offering response, an audio feedback signaling the correctness of the students' trail.

Noteworthy is that CS Hamlet is designed in the form of educational game. Game-learning has long been recognized as one of the features in helping students learn. For example, Dempsey et al. have studied the use of stimulation, adventure, arcade, board, puzzle and word games for promoting problem-solving and decision-making skills, linked to specific topics [45]. Designed in arcade mode with restricted numbers of trails (Fig. 1), as indicated by the bullets in the left hand corner, question in CS Hamlet is inter-related with each character in Hamlet and the difficulties of each question increase progressively. Such game design is in line with [46] about challenges in game learning where challenges are introduced gradually. As the challenges progress, students could acknowledge development of the main characters throughout the story. Fig. 1 illustrates the progression of challenging.

Students learning through educational apps embodied with a behaviourist learning theory therefore engage in gameplay cycle with 'repeated judgment-behaviour-feedback loops' [47] where judgment are made based on their built-in knowledge of Hamlet as well as the scenarios, questions and feedback put forward in the game.

\section{CONCLUSION AND IMPLICATIONS}

The above illustration presents our pilot study of Shakespeare apps in relation to the learning theories. Further case studies in our project show that mobile apps could facilitate teaching and learning. This project raises the awareness of learning Shakespeare through mobile apps to learners, teachers and apps designers. Learning will gradually extend beyond the classroom and embedded in learner's real and virtual environments [29]. Regarding teaching Shakespeare, teachers could recommend the use of Shakespeare apps to students so as to reinforce and encourage learning from a multiple pedagogical perspectives outside classroom. Instructional designers and educators could be informed about the potential of apps as learning tools for students. The study informs apps developers into ways of designing mobile applications with multiple learning perspectives.

Mobile apps challenge the established pedagogical practices and the effectiveness of traditional materials. The technological affordances of mobile apps and appropriate learning theories allow teachers and students to adopt mobile learning in an innovative way [48]. This study has illuminated the potential for using mobile apps to learn Shakespeare in an innovative way. Within classrooms, how teachers incorporate Shakespeare apps into their teaching activities would be an issue of discussion. We must ensure that the English Language Arts teaching can include mobile apps as a practice in productive ways [29] so that students could learn Shakespeare from multiple dimensions. The following research directions are worthwhile for further consideration:

1) What are the best mobile-learning activities for learning Shakespeare?

2) Do Shakespeare apps increase student motivation? If yes, why do teachers/students find useful?

3) How can Shakespeare apps enable more engagement and interactivity in classrooms?

4) Could Shakespeare apps complement Hong Kong Diploma of Secondary Education (HKDSE) Examination curriculum from ELA teachers' point of view?

5) How do Shakespeare apps change teacher pedagogy?

6) How can we best enhance learning by exploiting mobile technologies to designing ELA material?

In addition to the above considerations, ways to enhancing students' understandings and interpretation of Shakespeare apps merit closer investigation. One of the possible approaches would be analysing Shakespeare apps from a multimodal perspective so as to examine the meaning-making resources construed by the apps. Multimodality regards "representation, communication and interaction" as more than just language [49]. There is a growing interest among professionals, academics, and students in multimodality [49] because of the considerable social change in contemporary society in which new needs and access to information and knowledge, and linkages across local and global boundaries are arising in society. These changes are closely related to the advancement of technologies and visual representational methods which have created a great effect on the communication landscape of the twenty-first century [49]. The modern world has developed into "a visual phenomenon" that combines "looking, seeing and knowing" [50]. Bhatia, Flowerdew and Jones [51] also state that multimodality is especially crucial when analysing electronic media. Especially on mobile apps, various modes of presentation are converged with text, visual images, graphic design, sound video and animations. The "increasing interest in multimodality" [49] suggests the importance of integrating multimodality analysis into the investigation of Shakespeare apps. We believe that multimodal analysis of Shakespeare apps could be conducted in the following ways:

1) How do the multimodal resources in ELA apps facilitate teaching and learning of Shakespeare apps?

How do these multimodal resources construe meanings?

How do these multimodal resources co-construe meanings?

2) What are some of the frequently occurring visual resources in Shakespeare apps?

We believe that Shakespeare apps could be analysed from a multidimensional approach. English Language Arts teachers and learners would benefit from the research outcomes from this paper.

\section{REFERENCES}

[1] Email Marketing Reports. (November 2012). [Online]. Available: http://www.email-marketing-reports.com/wireless-mobile/smartphone -statistics.htm 
[2] D. Wooldridge and M. Schneider, The Business of iPhone App Development: Making and Marketing Apps that Succeed, APRESS, 2010, ch. 4, pp. 61-106.

[3] A. Kukulska-Hulme, "Will mobile learning change language learning?" Recall for European Association for Computer Assisted Learning, vol. 21, no. 22, pp. 157-165, May 2009.

[4] R. H. Jones and C. A. Hafner, Understanding Digital Literacies: A Practical Introduction, Routledge, London and New York: Taylor \& Francis Group, 2012, ch. 1, pp. 1-15.

[5] MoLeNet. (November 2012). What Is the Mobile Learning? [Online]. Available: http://www.molenet.org.uk/

[6] C. O'Malley, G. Vavoula, J. P. Glew, J. Taylor, M. Sharples, and P. Lefrere. (June 2013). MobiLearn: WP-Guidelines for Learning/Teaching/Tutoring in a Mobile Environment. [Online]. Available: http://www.mobilearn.org/download/results/guidelines.pdf

[7] J. Kadirire, "Mobile learning DeMystified," in The Evolution of Mobile Teaching and Learning, R. Guy, Ed., Santa Rosa, California: Informing Science Press, 2009, ch. 1, pp. 1-14.

[8] M. Ally, "Designing effective learning objects for distance education," in Online Education Using Learning Objects, R. McGreal, Ed., London: Routledge Flamer, 2004, pp. 76-86.

[9] M. Ally, "Using learning theories to design instruction for mobile learning devices," presented at the Third International Conference on Mobile Learning, Rome, 2004.

[10] M. Davis, N. Good, and R. Sarvas. (November 2012). From Context to Content: Leveraging Context for Mobile Media Metadata. [Online]. Available:

http://sigmobile.org./mobisys/2004/context_awareness/papers/davis.p df

[11] N. Friesen, S. Hesemeier, and T. Roberts, "CanCore: Guidelines for learning object metadata," in Online Education Using Learning Objects, R. McGreal, Ed., London: Routledge/Falmer, 2005, ch. 17, pp 204-213.

[12] E. Magusin, K. Johnson, and T. Tin. (November 2012). Library services: Designing the digital reading room to support online learning. The $19^{\text {th }}$ Annual Conference on Distance Teaching and Learning. [Online].

Available: http://www.uwex.edu/disted/conference/Resource_library/proceeding s/03 65.pdf

[13] R. McGreal, T. Tin, B. Cheung, and S. Schafer, "The athabasca university digital reading room: Library resources for mobile students," presented at the MLearn 2005 Conference, Qawra, Malta: IADIS, 2005

[14] J. Baggaley. (November 2012). M-learning how to M-teach. Diverse Newsletter. [Online].

Available: http://caslt.lancs.ac.uk/diverse/diversen11104jbl.htm

[15] F. Lin, Designing Distributed Learning Environments with Intelligent Software Agents, Hershey, PA: Idea Group Publishing, 2004, ch. 3, pp. $67-114$.

[16] L. Esmahi and F. Lin, "A multiagent framework for an adaptive e-learning system," in Designing Distributed Learning Environments with Intelligent Software Agents, F. Lin Ed., Hershey, PA: Idea Group Publishing, 2004, ch. 8, pp. 218-241.

[17] S. So, "The development of a SMS-based teaching and learning system," Journal of Educational Technology Development and Exchange, vol. 2, no. 1, pp. 113-124, October 2009.

[18] University of Hong Kong. (November 2012). HKU launches mobile learning platform to enhance quality of learning and teaching Inter-school mobile quiz contest to promote mobile learning and Olympics. Published Report from Department of Electrical and Electronic Engineering at Hong Kong University. [Online]. Available: www.eee.hku.hk/achievements/achievements/mlearning.htm.

[19] S. T. Daily, "Primary school purchase 150 iPads: Apps enhance learning motivation," Sing Tao Daily, March 23, 2011.

[20] The Sun, "Primary students learn golden saying through App," The Sun, May 22, 2012

[21] L. Gooch, "Much ado about studying the Bard," South China Morning Post, March 1, 2008.

[22] B. Tashman, "Sorry ernie - TV isn't teaching," New York Times, November 12, 1994.

[23] L. Kissler, "Teaching Shakespeare through film," in Teaching Shakespeare into the Twenty-First Century, R. E. Salomone \& J. E. Davis, Eds., Athens: Ohio University Press, 1997, ch. 6, pp. 201-207.

[24] M. Mullin, "Shakespeare on the web," in Shakespeare Matters: History, Teaching Performance, L. Davis, Ed., Delaware, Newark, London, 2003, pp. 119-137.

[25] A. Suen and A. Fung, "Discovering the brand of Asia world city: A discourse analysis of Hong Kong tourist mobile apps," International
Proceedings of Economics Development and Research. Language, Medias and Culture III, pp. 10-14, vol. 77, Singapore, 2014.

[26] P. Rainger, "Usability and accessibility of PDAs in education," MLEARN 2003 Learning with Mobile Device, London: Learning and Skills Development Agency, 2003, pp. 56- 57.

[27] P. Lonsdale and H. Beale, "Towards a dynamic process model of context," presented at the First International Workshop on Advanced Context Modelling, Reasoning and Management, Nottingham, England, 2004

[28] R. C. Small, Guidelines for the Preparation of Teachers of English Language Arts, Urbana, IL: National Council of Teachers of English, 1996.

[29] L. Naismith, P. Lonsdale, G. Vavoula, and M. Sharples. (November 2012). Literature review in mobile technologies and learning. Report 11: Futurelab Series. A Report for NESTA Futurelab. [Online]. Available:

http://www2.futurelab.org.uk/resources/documents/lit_reviews/Mobil e_Review.pdf

[30] P. Thornton and C Houser, "Using mobile phones in education," in Proc. $2^{\text {nd }}$ International Workshop on Wireless and Mobile Technologies in Education, pp. 3-10, Taiwan: IEEEE, 2004.

[31] W. B. Wood, "Clicker: A teaching gimmicks that works," Developmental Cell, vol. 7, no. 6, pp. 796-798, 2004

[32] J. Bruner, Toward a Theory of Instruction, New York: Newton, 1966.

[33] V. Colella, "Participatory simulations: Building collaborative understanding through immersive dynamic modelling," Journal of Learning Sciences, vol. 9, no. 4, pp. 471-500, 2000.

[34] E. Klopfer and K. Squire, "Environmental detectives: The development of an augmented reality platform for environmental simulations," Educational Technology Research and Development, vol. 56, no. 2, pp. 203-228, 2009.

[35] Y. Rogers et al., Learning through digitally-augmented physical experiences: Reflections on the Ambient Wood project, Equator Working Paper, 2002.

[36] N. Proctor and P. Burton, "Tate Modern multimedia tour pilots," MLEARN 2003 Learning with Mobile Device, London: Learning and Skills Development Agency, 2003, pp. 127- 130.

[37] C. Cortez et al., "Teaching science with mobile computer supported collaborative learning," in Proc. $2^{\text {nd }}$ International Workshop on Wireless and Mobile Technologies in Education, Taiwan: IEEEE, 2004, pp. 67-74

[38] J. Attewell and C. Savill-Smith, "M-learning and social inclusion: Focusing on learners and learning," in MLEARN 2003 Learning with Mobile Device, J. Attewell, G. D. Bormida, M. Sharples, and C. Savill-Smith, Eds., London: Learning and Skills Development Agency, 2003, pp. 3-12.

[39] J. Wood, A. Keen, N. Basu, and S. Robertshaw, "The development of mobile applications for patient education," in Proc. Designing for User Experiences, San Francisco: Dux, 2003, pp. 1-4.

[40] D. Perry, Handheld Computers (PDA) in Schools, Coventry, UK BECTA, 2003

[41] B. F. Skinner, The Technology of Teaching, New York: Appleton-Century-Crofts, 1968.

[42] J. Lave and E. Wenger, Situated Learning: Legitimate Peripheral Participation, Cambridge: CUP, 1991.

[43] A. M. Tough, The Adult's Learning Projects, Toronto, Ontario Institute for Studies in Education, 1971.

[44] G. Conole, M. Dyke, M. Oliver, and J. Seale, "Mapping pedagogy and tools for effective learning design," Computers and Education, vol. 43 , no. 1, pp. 17- 33, 2004.

[45] Dempsey et al., "Forty simple computer games and what they could mean to educators," Simulation and Gaming, vol. 33, no. 2, pp. 157-168, 2002.

[46] F. D. Laramee, Game Design Perspectives, Hingham, MA: Charles River Media, 2002.

[47] R. Garris, A. Robert, and E. D. James, "Games, motivation, and learning: A research and practice model," Simulation and Gaming, vol. 33, no.4, pp. 441-467, 2002.

[48] A. Herrington and J. Herrington. (November 2012). Authentic mobile learning in higher education. [Online]. Available: http://www.aare.edu.au/07pap/her0131.pdf

[49] C. Jewitt, The Routledge Handbook of Multimodal Analysis, 1st ed. London: Routledge, 2009.

[50] C. Jenks, Visual Culture, 1st ed., London: Routledge, 1995.

[51] V. K. Bhatia, R. H. Jones, and J. Flowerdew, "Approaches to discourse analysis," in Advances in Discourse studies, R. H. Jones, V. K. Bhatia and J. Flowerdew, Eds., New York: Routledge, 2008, ch. 1, pp. 12-18. 
Amy Suen is an instructor at the Department of English of the Hong Kong Polytechnic University. Her teaching areas are in professional communication in English, corporate communication, intercultural communication, pragmatics and corpus linguistics. Amy received both her $\mathrm{PhD}$ and the bachelor degree from the Department of English, the Hong Kong Polytechnic University. Her PhD thesis is 'Hotel websites as corporate communication'. She was a visiting scholar at the Macquarie University, Sydney, Australia in 2009 during her PhD study. Dr. Amy Suen's curren research interests are professional communication, multimodality, critical genre analysis, mobile learning and mobile applications in tourism and hospitality industry.
Andy Fung studies in the Department of English of the Hong Kong Polytechnic University. He received his bachelor degree. He furthers his study and works as a research assistant. He is currently a PhD candidate at the department. He is also a part-time tutor in the School of Arts \& Social Sciences, the Open University of Hong Kong. His primary research interest is systemic functional linguistics (SFL), with a particular focus in studying English and Chinese from a systemic functional point of view. His current research interests focus on the application of SFL in a variety of professional communications in Hong Kong context, including healthcare communication and mobile applications. 